\title{
The effect of cryogenic machining of S2 glass fibre composite on the hole form and dimensional tolerances
}

\author{
Ugur Koklu $^{1} \cdot$ Sezer Morkavuk ${ }^{1} \cdot$ Carol Featherston $^{2} \cdot$ Malik Haddad $^{3} \cdot$ David Sanders $^{3} \cdot$ Muhammad Aamir $^{4}$. \\ Danil Yu Pimenov ${ }^{5}$ Khaled Giasin ${ }^{3}$
}

Received: 13 January 2021 / Accepted: 20 April 2021 / Published online: 3 May 2021

(C) The Author(s) 2021

\begin{abstract}
S2 glass fibre reinforced epoxy composites are widely used in aeronautical applications owing to their excellent strength to weight ratio. Drilling glass fibres can be cumbersome due to their abrasive nature and poor thermal conductivity. Moreover, the use of conventional coolants is not desirable due to contamination and additional costs for cleaning the machine part. An alternative is to use environmentally friendly coolants such as liquid nitrogen $\left(\mathrm{LN}_{2}\right)$ which have been previously employed in machining metals and composites. The current study investigates the effect of drilling S2 glass fibre composite in a bath of $\mathrm{LN}_{2}$. The study aims to evaluate the effect of spindle speed, feed rate and the presence of cryogenic cooling on the form and dimensional tolerances of the hole (hole size, circularity, cylindricity and perpendicularity). Design of experiments and analysis of variance (ANOVA) were used to determine the contribution of the input parameters on the analysed hole quality metrics. Results indicated that drilling S2 glass fibre in a cryogenic bath increased hole size significantly beyond the nominal hole diameter. The hole circularity and cylindricity were reduced compared to holes drilled under dry condition under all cutting parameters due to enhanced thermal stability during the drilling process. The current study aims to provide the scientific and industrial communities with the necessary knowledge on whether cryogenic bath cooling strategy provides better hole quality output compared to dry drilling and other cryogenic cooling strategies which were previously reported in the open literature.
\end{abstract}

Keywords Hole size $\cdot$ circularity $\cdot$ Perpendicularity $\cdot$ Cylindricity $\cdot$ S2 glass fibre

\section{Introduction}

Glass fibre is the original fibre reinforcement of modern composites; it is mainly used as structural reinforcement in civil, marine and aviation applications. Between 2020 and 2025, the market share of glass fibre composites will be the largest in terms of volume and value [1]. Glass fibres dominate the composite market due to their low cost and excellent
Khaled Giasin

khaled.giasin@port.ac.uk

Ugur Koklu

ugurkoklu@gmail.com

Sezer Morkavuk

sezermorkavuk@kmu.edu.tr

Carol Featherston

featherstonca@cardiff.ac.uk

Malik Haddad

malik.haddad@port.ac.uk

David Sanders

david.sanders@port.ac.uk

Muhammad Aamir

m.aamir@ecu.edu.au
Danil Yu Pimenov

danil_u@rambler.ru

1 Department of Mechanical Engineering, Faculty of Engineering, Karamanoglu Mehmetbey University, Karaman, Turkey

2 School of Engineering, Cardiff University, The Parade, Cardiff CF24 3AA, UK

3 School of Mechanical and Design Engineering, University of Portsmouth, Portsmouth PO1 3DJ, UK

4 School of Engineering, Edith Cowan University, Joondalup, WA 6027, Australia

5 Department of Automated Mechanical Engineering, South Ural State University, Lenin Prosp. 76, Chelyabinsk 454080, Russia 
performance such as high strength, lightweight and durability. There are many types of glass fibres such as E, R and S/S2 and less known such as A, D and C. S-glass was originally developed for military applications in the 1960s [2], Composites made from S2 glass was developed for commercial applications in later stages as a lower-cost version of S-glass [2]. Sglass-based composites are used in aerospace applications due to the higher contents of silicon and aluminium oxides in the fibres which gives them greater elongation and lower density relative to other types of glass fibres. In, addition, S and S2 glass fibres have the highest tensile strength among all other types of glass fibres [3]. Therefore, they are attractive for use in aerospace applications because of their relative light weight, high strength and stiffness. For example, S2 glass fibre prepregs are bonded with aluminium metallic sheets to form a stack of hybrid metal-composite commercially known as GLARE® fibre metal laminates. GLARE® laminates are installed in the fuselage of the Airbus A380 due to their excellent fatigue and impact resistance. Aeronautical structures are usually produced in large panels that require trimming to bring them to the right dimensions followed by drilling a large number of holes to install the fasteners used for the assembly of different structures together. Drilling glass fibre composites is challenging since the fibres have abrasive nature and the laminate have poor thermal conductivity. This in return would lead to rapid tool wear and lower hole quality due to increased chance for delamination and out-of-range hole tolerances. Moreover, it is estimated that poor connecting holes in aircraft structures account for up to $80 \%$ of fatigue cracks in the aircraft body [4,5]. Using oil-based or water-based coolants is an attractive choice to overcome tool wear and increase temperatures during the machining process [6]. However, glass fibre composites are prone to moisture absorption which would reduce their strength and structural performance. An alternative is to use a non-water-based or oil-based coolant such as liquid nitrogen and carbon dioxide which are also known as cryogenic coolants. The use of cryogenic coolants was mainly proposed for machining hard to cut materials such as titanium and steel alloys [7-9]. Cryogenic coolants are environmentally friendly, providing a clean machining process without the need to dispose or handle the coolant waste [10]. Even the produced chip is free from oil and water contaminations, and therefore, the collected chips could be easily recycled [11].

There are a significant number of studies in the open literature on drilling glass fibre composites. A table summary on previous research was previously reported by Giasin et al. [12]. Previous researchers studied the effects of cutting parameters [13-17], drill type, geometry and coating [15, 18-20] on developed cutting forces [21-24], tool wear [22, 25, 26] and several hole quality metrics such as delamination at exit and entry sides of the hole [18, 24, 27, 28], surface roughness [14, 27, 29], hole size and circularity [30-32]. Singh et al. [33] reported that the thrust force increased with the increase of the feed rate and the drill point angle. Similar findings were also found in the work carried out by Ișik et al. [34], Davim et al. [35, 36], Kilickap [37, 38] and Ramesh et al. [39]. Mohan et al. [40] reported that delamination is highly influenced by cutting parameters and workpiece thickness. They recommended using high cutting speed and low feed rate to minimise delamination at the exit side of the hole. Similar observations were reported by Kilickap [37]. However, contradicting results were reported by Palanikumar et al. [19] found that the delamination decreases as the spindle speed is increased. This might be due to the different tool geometry, cutting parameters or type of material machined in their studies. Ranganathan et al. [41] found that the feed rate had more than three times the effect of cutting speed on the cutting forces, surface roughness and delamination. Similar results were also reported by Ișık et al. [34] and Kilickap [37] and Sarma et al. [42] and Sureshkumar et al. [43]. Işık et al. [34] reported that increasing the number of drill flutes and point angle increased the delamination factor at the exit which was mainly due to increased chip load. Kilickap [44] and Palanikumar et al. [19] also reported that delamination is reduced when the drill has a smaller point angle. Davim et al. [35] found that the drill type and its geometry had an impact on drilling performance of GFRP. Their results showed that the cutting pressure produced by Brad and Spur drills is lower than that produced by stub length drills; this in return produced lower surface roughness and delamination. However, in another study by Latha et al. [36], it was reported that Brad and Spur drills produced higher thrust force than step and multi-facet drills. Mathew et al. [45] also reported that trepanning tools could reduce thrust force by up to $50 \%$ compared to twist drills when drilling GFRP, but hole accuracy must be carefully monitored by maintaining the accuracy of the cutting edges. In another study, Singh et al. [46] found that using four facet drills for drilling GFRP is not recommended due to very high cutting forces. In the other hand, 8 facet and jobber drills produced lower cutting forces. Abrao et al. also reported that the cutting tool geometry and material have significant effect on cutting forces and resulting delamination, a smaller the drill point angle and low feed rates were recommended for drilling CFRP and GFRP materials [47-49]. Rubio et al. [49] found that delamination is minimal when drilling GFRP at very high spindle speeds of 40,000 rpm, irrespectively of the feed speed employed. Davim et al. [35] also reported that the increase of the feed rate increased surface roughness while increasing the cutting speed decreased it. Similar trends were found in the work of Sarma et al. [42] which also reported that depth of cut shows only the limited effect in machining of GFRP composites. Latha et al. [36] reported that the cutting forces increased with the increase of the drill diameter. Similarly, Bosco et al. [50] reported that the higher the drill diameter, the greater the delamination factor will be due to the larger contact area between the cutting tool and the workpiece. Mehbudi et al. [23] 
found that using ultrasonic assisted drilling of GFRP reduced cutting forces and delamination by up to $50 \%$ compared to conventional drilling. Mudhukrishnan et al. [38] found that the cutting tool material can significantly affect cutting forces during drilling of GFRP. Their results showed that HSS drills produced higher cutting forces and delamination in comparison to tipped carbide and carbide drills due to lower hardness and faster tool wear. However, it was not reported whether all the drills had same geometry which might had some influence on the cutting forces. Similar results were observed by Arul et al. [20], which found that coated and uncoated HSS drills showed similar performance and faster tool wear compared to that observed using carbide drills. Indeed, Faria et al. [51] reported similar results where they found that HSS drills tended to produce higher cutting forces than coated and uncoated carbide drills. Moreover, the hole diameter and circularity decreased considerably when using HSS drill as the number of drilled increased which was due to rapid tool wear, while coated and uncoated carbide drills showed stable hole diameter when drilling up to 10,000 holes and stable hole circularity when drilling up to 24,000 holes. Kim et al. [52] reported that carbide drills produced oversized holes, while undersized holes were produced when using HSS drills. Sureshkumar et al. [43] found that the hole circularity and delamination increased with the feed rate increase. Vankanti et al. [30] also found that increasing cutting tool geometry such as its chisel edge and point angle in addition to the feed rate significantly increased hole circularity. The severity of damage in the hole is affected by the angle between fibre orientation and the cutting edge of the tool. The fibres are subjected to alternating torsion and compression prior shearing by the cutting edges. That in return would produce an ellipse-like-shaped hole with its minor axis being same to the fibre direction [51]. Rubio et al. [32] found that the spindle speed was the main parameter that influences the hole circularity, while the point angle of the drill and feed rate had lesser effect. Other studies also reported that cryogenically treated cutting tools or using chilled air reduced delamination factor when drilling GFRP and CFRP [53, 54]. After extensive review of literature, on drilling GFRP, it was found that there are no studies on the drilling of S or S2 glass fibre composites are available in the open literature except for one study conducted by Giasin et al. [55]. In their study, results showed that the cutting forces and hardness increased when drilling in a bath of $\mathrm{LN}_{2}$ compared to dry drilling, while the surface roughness was reduced. Therefore, the current study aims to fulfil this gap and report on the effects of cutting parameters and the use of cryogenic liquid nitrogen cooling bath on the form and dimensional tolerances of holes in $\mathrm{S} 2$ glass fibre composite. In addition, holes machined in aeronautical structures must meet strict geometrical tolerances due to their direct impact on fatigue life of structure during their service. Indeed, according to historical data on fatigue in aircraft components, $55 \%$ of in-service failures in aircraft components occurs due to fatigue related to poor hole quality. Fastener holes tend to produce regions of stress concentrations at which fatigue cracks propagate [56]. Table 1 shows previous literature on hole form and dimensional tolerances reported when drilling CFRP and GFRP materials. The results indicated that achieving tight hole tolerances in composite material is a major challenge especially when no coolants are used. In addition, the literature indicates that little attention is given to study the hole dimensional and geometric deviations after machining GFRPs. Therefore, the specific objective here is to determine the beneficial and adverse effects of drilling S2 glass fibre composite in a bath of $\mathrm{LN}_{2}$. Additionally, dry drilling tests were carried out to compare the hole quality output against results from cryogenic drilling tests. Statistical design of experiments was used to formulate the design study, and ANOVA and Pareto charts were used to further highlight the effect and percentage contribution of the cutting parameters and presence/absence of $\mathrm{LN}_{2}$ coolant on the studied output parameters (hole size, circularity, cylindricity and perpendicularity). Improving the hole dimensional and geometrical tolerances throughout the interior surface of the hole indicates high-quality holes [63], a pre-requisite in aerospace structural applications. The current study also aims to highlight the considerable contribution and drawbacks of cryogenic bath cooling as opposed to dry drilling of GFRP composites specifically for use in aerospace applications.

\section{Materials and method}

This section presents the materials and method used. Subsection 2.1 presents work piece and cutting tool. Subsection 2.2 presents measurement of hole form, dimensional tolerances and hole inner surfaces.

\subsection{Workpiece and cutting tool}

An S2 glass fibre and FM94 adhesive epoxy workpiece was used in the current study for drilling tests. The workpiece was square shaped with 240-mm edge length and a thickness of $7.18 \mathrm{~mm}$ (54 prepregs with an approximate prepreg thickness of $0.133 \mathrm{~mm}$ ) as shown in Fig. 1a. The prepregs were made from S2 glass fibres embedded with FM94 adhesive film [64]. The S2 glass fibres were approximately $10 \mu \mathrm{m}$ thick; the fabricated laminate was unidirectional (UD) with a symmetric stacking sequence of $\left[0^{\circ} / 90^{\circ}\right]_{27 \mathrm{~s}}$ as shown in Fig. 1a. The laminate was cured in the autoclave for approximately $300 \mathrm{~min}$ at a pressure of 6 bars [65] as shown in Fig. 1b. TiAlN-coated carbide twist drills with a diameter of $\varnothing 6 \mathrm{~mm}$ were used. The drills had a point angle of $140^{\circ}$ and a helix angle of $30^{\circ}$ as shown in Fig. 1c. Two sets of drilling experiments were carried out in the current study; the first set of 
Table 1 Range of hole size an circularity in previous studies on drilling composite materials

\begin{tabular}{llll}
\hline Workpiece material & Hole size $(\mu \mathrm{m})$ & Circularity $(\mu \mathrm{m})$ & Reference \\
\hline GFRP & - & $4-41$ & {$[43]$} \\
GFRP & - & $42.5-312$ & {$[30]$} \\
CFRP & +20 to +950 & $80-250$ & {$[57]$} \\
CFRP & - & - & {$[58]$} \\
CFRP & - & $6-25$ & {$[59]$} \\
Glass/phenolic-woven fabric & +3 to +13 & - & {$[31]$} \\
CFRP & -10 & $6-25$ & {$[59]$} \\
CFRP & -4 to +8 & $5-7$ & {$[60]$} \\
E-glass & -20 to +100 & $12-188$ & {$[32]$} \\
E-glass & -200 to +50 & $9-105$ & {$[51]$} \\
Si3N4 composite material & - & $73-171$ & {$[61]$} \\
CFRP & -70 to +20 & $780-900$ & {$[62]$} \\
\hline
\end{tabular}

tests were carried out under dry conditions, and the second set of tests was carried out by placing the workpiece in a bath of liquid nitrogen as shown in Fig. 1d.

The cutting parameters used in the current study are given in Table 2. The choice of cutting parameters was based on previous literature and recommended cutting parameters by the cutting tool supplier. Three levels of feed rate $(f)$ and spindle speed $(n)$ and two levels for cooling (dry and cryogenic) were used. The aim was to form a full factorial $\mathrm{L}_{18}(18$ holes) design of experiment study to employ ANOVA statistical analysis to find the percentage contribution of the spindle speed, feed rate and presence/absence of coolant on the analysed hole metrics. A total of three drilling tests were carried out for cryogenic and drilling experiments; therefore, all reported results thereafter represent the average of the three tests.

\subsection{Measurement of hole form and dimensional tolerances and hole inner surfaces}

A CMM (coordinate measurement machine) was used to measure the hole form and dimensional tolerances. The CMM used was a Mitutoyo Crysta-Apex S776 equipped with a Renishaw PH10MQ fitted with an AM2 adjustment module and a SP25M scanning probe system as shown in Fig. 2. The measurements for hole size and circularity were taken at $1 \mathrm{~mm}$ below and above the top and bottom surfaces of the workpiece. The two positions are named top and bottom thereafter
Fig. 1 a) Workpiece fibre orientation and number of layers. b) Autoclave and manufacturing of the composite workpiece. $\mathbf{c})$ Schematic of the drill bits used in the study. d) Setup of the workpiece inside the cryogenic bath inside the $\mathrm{CNC}$ machine [12] a)

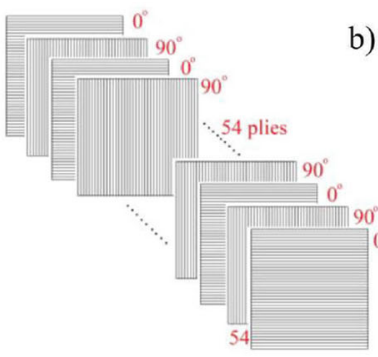

b)



c)

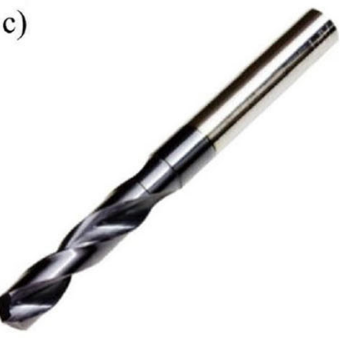

d)

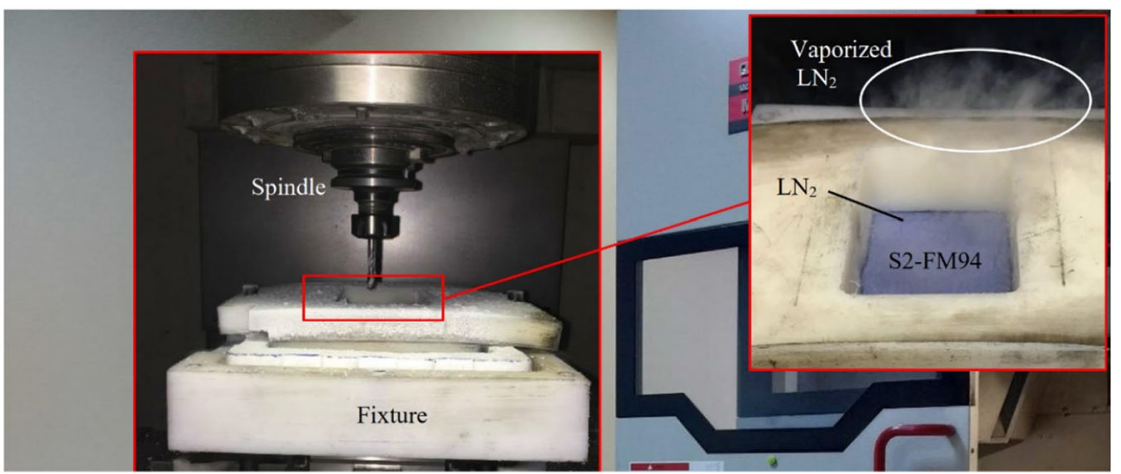


Table 2 Design of experiment input parameters and their levels

\begin{tabular}{llcc}
\hline Factor & Low level & Medium level & High level \\
\hline Spindle speed (rpm) & 3000 & 5000 & 7000 \\
Feed rate (mm/min) & 300 & 500 & 700 \\
Cooling & No (dry) & Cryogenic bath of tool and workpiece & \\
\hline
\end{tabular}

in the manuscript discussion section. Additional measurement was taken at the middle of the workpiece in order to get measurements for the hole circularity and perpendicularity. After the CMM inspection, the holes were cross-sections from their centre and were observed using A Hitachi SU5000 field emission SEM (scanning electron microscope) used to visualize the borehole surface quality.

\section{Results and discussions}

This section presents the results and discussion for the collected hole metrics. Subsection 3.1 presents hole size and circularity analysis. Subsection 3.2 presents hole cylindricity and perpendicularity analysis and inspection of hole inner surfaces and post machining cutting tool conditions.

\subsection{Hole size and circularity analysis}

The spindle speed $(n)$ and feed rate $(f)$ cutting parameters play an important role to assess the hole quality during machining [66]. Deviation from the nominal size is important for the performance of any machined part; therefore, the hole size requires more attention as much as surface roughness. Previous study reported that during the drilling process the heat that flows into the workpiece from the cutting zone raises its temperature, and the resulting thermal distortions to the workpiece geometry [67], which is partially due to the different thermal expansion coefficient in the laminate due to different fibre orientations. In the aerospace industry, holes must meet certain tolerances and standards it is desired that the holes be close to the nominal diameter for riveting [68, 69]. Figure 3 shows the average hole size under different cutting parameters for dry and cryogenic conditions at top and bottom locations. Overall, the hole size deviation from the nominal size at top of the hole is more than at the bottom of the hole in dry drilling environment, while the holes obtained in the cryogenic condition were found less deviated from the nominal size at the top as compared with the bottom side. Additionally, the difference between the entrance and exit diameters in holes drilled using cryogenic cooling were less than those drilled under dry conditions. This would indicate that using cryogenic cooling provide more consistency in hole size throughout its depth. Moreover, under dry conditions, the difference between the entrance and exit diameters tends to increase at the higher spindle speeds which is in agreement

Fig. 2 Hole metrics measurement using CMM machine
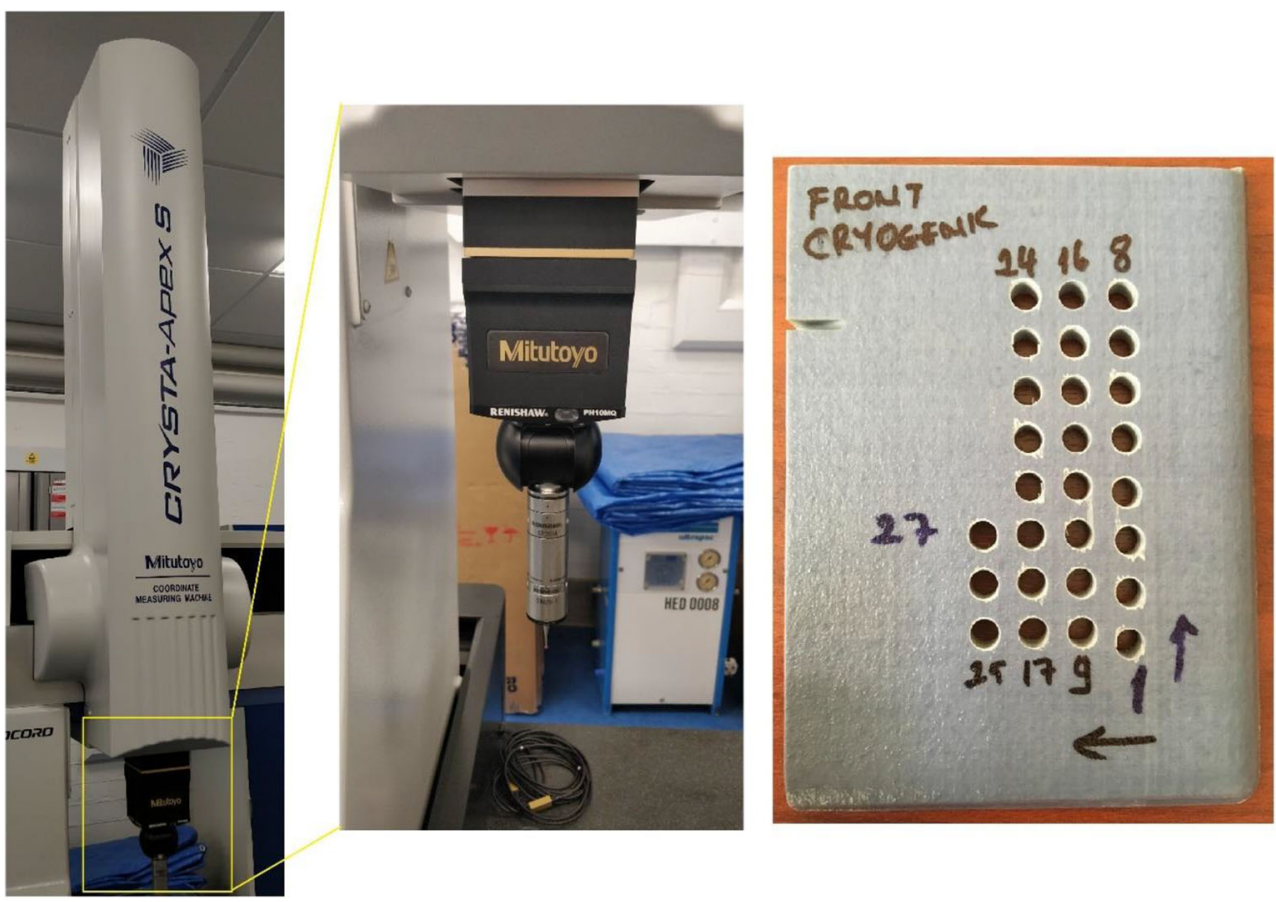

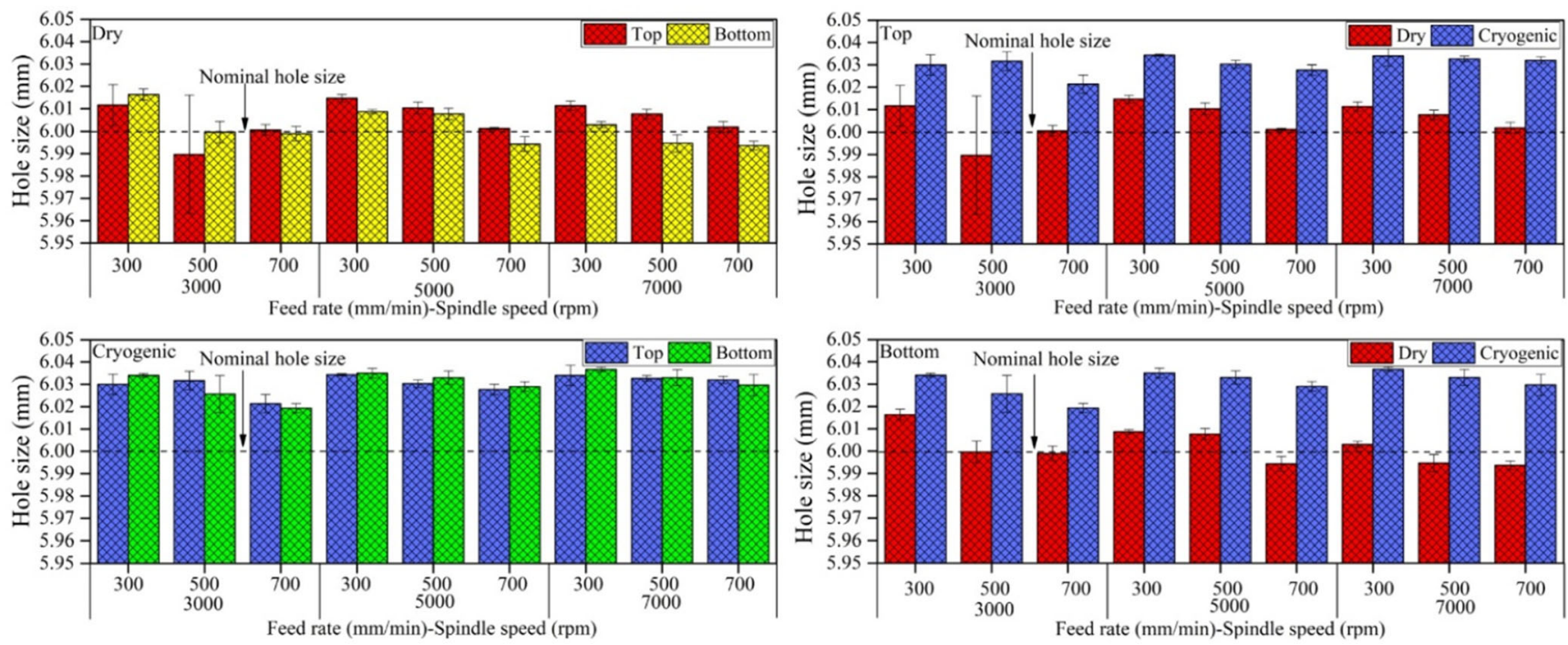

Fig. 3 Average hole size at the top and bottom of holes in dry and cryogenic conditions

with previous study on drilling composites [70]. This is due to the rise in the drilling temperature that increases the mechanical abrasion onto the hole wall enlargement [70]. Nevertheless, the holes produced in dry drilling were closer to the drill nominal diameter than those obtained from the cryogenic drilling tests.

Overall, less deviation of holes from the nominal size was found with the increase in the feed rate in dry drilling. For hole size at the top, the minimum deviations of 6.0007 and $6.0213 \mathrm{~mm}$ and maximum values of 6.0147 and $6.0343 \mathrm{~mm}$ were found for dry and cryogenic conditions, respectively. The lowest $n=3000 \mathrm{rpm}$ and highest $f_{r}=700 \mathrm{~mm} / \mathrm{min}$ were the reason for the minimum deviation, while the maximum values were caused at the moderate $n=5000 \mathrm{rpm}$ and the lowest $f_{r}=300 \mathrm{~mm} / \mathrm{min}$. However, at the bottom of the hole size, the minimum deviated value for the dry condition was $5.9997 \mathrm{~mm}$ at the $n$ of $5000 \mathrm{rpm}$ and $f_{r}=700 \mathrm{~mm} / \mathrm{min}$, while for cryogenic condition, the minimum value of $6.0193 \mathrm{~mm}$ was obtained at the lowest $n=3000 \mathrm{rpm}$ and $f_{r}=300 \mathrm{~mm} / \mathrm{min}$.

Also, for dry conditions, the maximum deviated value of $6.0163 \mathrm{~mm}$ occurred when drilling at $n=3000 \mathrm{rpm}$ and $f_{r}=$ $700 \mathrm{~mm} / \mathrm{min}$, while in the case of cryogenic conditions, the maximum deviated value of 6.0367 was observed at $n=$ $7000 \mathrm{rpm}$ and $f_{r}=500 \mathrm{~mm} / \mathrm{min}$. The deviation of hole size due to the high $n$ was expected due to the increase in the chatter vibration which might take an important role in the accuracy of the drilled hole size and causes instability of the cutting tool [66]. ANOVA results and Pareto chart given in Table 3 and Fig. 5 show that the use of cryogenic coolant had the most significant impact on hole size at top and bottom with $65 \%$ and $80 \%$, respectively, followed by the feed, while the spindle speed did not seem to have any effect at all. The interaction between the cutting parameters and the coolant had a small impact on hole size in general.
Some researchers found that using flood coolants when drilling CFRP produced undersized holes [71]. On the contrary, other studies reported that holes produced in CFRP under mist spray cooling were significantly oversized [63]. The oversized holes were caused by the lack of effective lubricating and cooling when using mist spray cooling which led to thermal expansion of the cutting tool and therefore oversized holes. On average, holes drilled under dry conditions produced closest tolerances to the nominal dimension. This can be explained by the fact that the carbide tools - on average has a lower thermal coefficient of expansion $\left(5.2 \times 10^{-6} . \mathrm{C}^{-1}\right)$ [72] than the workpiece material (longitudinal direction, 3.9$6.1 \times 10^{-6} \cdot \mathrm{C}^{-1}$; transverse direction, 26.2-55.2 $\times 10^{-6} \cdot \mathrm{C}^{-1}$ ) [73], and as a result of cryogenic bath cooling, the workpiece contracts more than the cutting tool thus resulting in over cutting and thus oversized holes. In addition, when drilling under dry conditions, it is expected that cutting temperature will rise both the cutting tool and the workpiece leading to the expansion of the lamina; however, composites such as CFRP and GFRP have tendency to spring-back leading to shrinkage of drilled holes closer to their nominal diameter [74]. The current results disagree with previous studies $[63,75-78]$ on drilling CFRP and GFRP laminates using through tool cryogenic cooling which both reported reduced hole size when using cryogenic cooling compared to dry drilling. This could be attributed to the cooling strategy (i.e., cryogenic bath vs cryogenic through tool cooling) in which the later provides efficient cooling in terms of controlled coolant quantity and localisation on the hole cutting region and cutting tool. In another study, it was reported that indirect cryogenic cooling of composites provided better performance in terms of lowers thrust force and specific cutting energy consumption in comparison to continuous cooling. The advantageous of this cooling technique is that it avoided workpiece hardening 
Table 3 ANOVA data for measured output parameters

\begin{tabular}{|c|c|c|c|c|c|c|c|c|c|c|c|c|}
\hline \multirow[b]{2}{*}{ Source } & \multicolumn{2}{|c|}{ Hole size (top) } & \multicolumn{2}{|c|}{ Hole size (bottom) } & \multicolumn{2}{|c|}{ Circularity (top) } & \multicolumn{2}{|c|}{$\begin{array}{l}\text { Circularity } \\
\text { (Bottom) }\end{array}$} & \multicolumn{2}{|c|}{ Cylindricity } & \multicolumn{2}{|c|}{ Perpendicularity } \\
\hline & $\begin{array}{l}P \\
\text { value }\end{array}$ & Contribution & $\begin{array}{l}P \\
\text { value }\end{array}$ & Contribution & $\begin{array}{l}P \\
\text { value }\end{array}$ & Contribution & $\begin{array}{l}P \\
\text { value }\end{array}$ & Contribution & $\begin{array}{l}P \\
\text { value }\end{array}$ & Contribution & $\begin{array}{l}P \\
\text { value }\end{array}$ & Contribution \\
\hline Model & 0 & $80.95 \%$ & 0 & $95.79 \%$ & 0.017 & $56.22 \%$ & 0 & $81.43 \%$ & 0 & $86.66 \%$ & 0.642 & $32.14 \%$ \\
\hline Blocks & 0.226 & $1.74 \%$ & 0.422 & $0.22 \%$ & 0.085 & $6.82 \%$ & 0.371 & $1.12 \%$ & 0.876 & $0.10 \%$ & 0.131 & $8.63 \%$ \\
\hline Linear & 0 & $73.15 \%$ & 0 & $89.30 \%$ & 0.002 & $30.26 \%$ & 0 & $66.10 \%$ & 0 & $75.25 \%$ & 0.482 & $9.15 \%$ \\
\hline Spindle speed & 0.083 & $3.01 \%$ & 0.11 & $0.58 \%$ & 0.008 & $14.47 \%$ & 0.004 & $7.26 \%$ & 0 & $8.07 \%$ & 0.591 & $2.13 \%$ \\
\hline Feed rate & 0.017 & $5.19 \%$ & 0 & $8.57 \%$ & 0.077 & $7.11 \%$ & 0 & $18.00 \%$ & 0.001 & $6.46 \%$ & 0.262 & $5.57 \%$ \\
\hline Coolant & 0 & $64.95 \%$ & 0 & $80.15 \%$ & 0.014 & $8.68 \%$ & 0 & $40.85 \%$ & 0 & $60.71 \%$ & 0.4 & $1.45 \%$ \\
\hline $\begin{array}{l}\text { Two-way inter- } \\
\text { actions }\end{array}$ & 0.746 & $2.83 \%$ & 0 & $5.58 \%$ & 0.522 & $9.34 \%$ & 0.038 & $10.36 \%$ & 0.063 & $6.61 \%$ & 0.669 & $11.56 \%$ \\
\hline $\begin{array}{l}\text { Spindle } \\
\text { speed*Feed } \\
\text { rate }\end{array}$ & 0.78 & $0.98 \%$ & 0.019 & $1.70 \%$ & 0.568 & $3.84 \%$ & 0.012 & $8.26 \%$ & 0.256 & $2.19 \%$ & 0.293 & $10.31 \%$ \\
\hline $\begin{array}{l}\text { Spindle } \\
\text { speed*Coolant }\end{array}$ & 0.656 & $0.48 \%$ & 0 & $3.49 \%$ & 0.309 & $3.13 \%$ & 0.586 & $0.59 \%$ & 0.009 & $4.24 \%$ & 0.944 & $0.23 \%$ \\
\hline $\begin{array}{l}\text { Feed } \\
\text { rate*Coolant }\end{array}$ & 0.309 & $1.36 \%$ & 0.223 & $0.39 \%$ & 0.408 & $2.37 \%$ & 0.265 & $1.51 \%$ & 0.808 & $0.17 \%$ & 0.775 & $1.03 \%$ \\
\hline $\begin{array}{l}\text { Three-way inter- } \\
\text { actions }\end{array}$ & 0.242 & $3.23 \%$ & 0.259 & $0.69 \%$ & 0.133 & $9.79 \%$ & 0.159 & $3.86 \%$ & 0.032 & $4.70 \%$ & 0.842 & $2.80 \%$ \\
\hline $\begin{array}{l}\text { Spindle } \\
\text { speed*Feed } \\
\text { rate*Coolant }\end{array}$ & 0.242 & $3.23 \%$ & 0.259 & $0.69 \%$ & 0.133 & $9.79 \%$ & 0.159 & $3.86 \%$ & 0.032 & $4.70 \%$ & 0.842 & $2.80 \%$ \\
\hline Error & & $19.05 \%$ & & $4.21 \%$ & & $43.78 \%$ & & $18.57 \%$ & & $13.34 \%$ & & $67.86 \%$ \\
\hline Total & & $100.00 \%$ & & $100.00 \%$ & & $100.00 \%$ & & $100.00 \%$ & & $100.00 \%$ & & $100.00 \%$ \\
\hline
\end{tabular}

caused by direct contact with cryogenic coolant [79]. Therefore, the literature appears to support the fact that the cooling strategy have significant and variable effect on the resulting hole and dimensional tolerances when drilling composites. However, it is difficult to compare the results like to like from those studies with the current study due to many variations such as the cutting tool type, geometry, material type and location of hole size measurement along the hole depth. However, a conclusion can be made here that using cryogenic bath cooling during drilling S2 glass fibre composites would results in oversized holes compared to dry conditions or other cryogenic cooling strategies. This could be attributed to the increased hardness and cutting forces when using cryogenic bath cooling as reported in a previous study on drilling S2 glass fibre composites in a cryogenic bath [55]. Another reason for increased hole size using cryogenic bath creates an extremely low temperature environment for both the cutting tool and the workpiece which restricts the rise of cutting temperatures and prevents possible thermal expansions of both tool and workpiece, i.e., cutting occurs at $196{ }^{\circ} \mathrm{C}$ or close to it. This was confirmed by Rodríguez et al. [77] which reported that under dry drilling, the temperature measured at the tool tip can be more than ten times higher than that when using cryogenic cooling. In addition, drilling at very low temperatures, the composite becomes more brittle which causes a substantial increase in cutting forces, thereby increasing the probability oversized holes [80]. Another possible facto could be the tool wear and its effect on resulting hole quality; however, this does not apply in this study due to the limited number of holes drilled using each drill which did not promote significant tool wear as will be discussed in the later sections.

According to cutting tool manufactures, the aerospace industry's requirements for hole size is to have minimal deviation from its nominal diameter to guarantee excellent rivet performance [81]. Generally, significantly oversized or undersized holes are undesirable and would lead to rejection of the machined part. Riveted holes in aeronautical structures should comply with the recommended upper range of hole $\mathrm{H} 9$ (i.e., 0 to $+30 \mu \mathrm{m}$ ) tolerance as reported by aerospace manufacturers [81, 82]. According to Brinksmeier et al. [83], those tolerances are needed for holes created in the composite structures that make up parts of the wing and tail of an aircraft. However, more relaxed hole sizes were reported to be as much as $250 \mu \mathrm{m}$ [84]. In addition, cutting tool manufacturers previously reported that hole tolerances in aeronautical composite structures tended to have hole size deviations between \pm 20 and $\pm 40 \mu \mathrm{m}[81,85]$. In the current study, the deviation of hole size under cryogenic condition ranged between 21.33 and $34.33 \mu \mathrm{m}$ at top and between $19.67 \mu \mathrm{m}$ and $36.67 \mu \mathrm{m}$ at the 
bottom. Similarly, the deviation of hole size under dry condition ranged between -10.33 and $14.67 \mu \mathrm{m}$ at top and between 16.33 and $-6.33 \mu \mathrm{m}$ at the bottom. This means that the range of the hole size reported in this study were within the allowable range required in aerospace applications and only undersized holes must undergo an additional reaming process to enlarge them [68].

Figure 4 shows the average circularity for dry and cryogenic tests at top and bottom locations. The minimum hole circularity of $0.0077 \mathrm{~mm}$ and $0.0033 \mathrm{~mm}$ values for dry and cryogenic conditions, respectively, were observed at the top of the hole size. For both the drilling conditions, these minimum values were obtained at the moderate $n=5000 \mathrm{rpm}$ and the lowest $f_{r}=300 \mathrm{~mm} / \mathrm{min}$. This indicates that lower feed rates produce holes with minimum circularity which was also reported in previous studies $[60,76]$. The increase in hole circularity with increasing feed rate is related to the increase in the thrust force which increases the radial force that have direct influence on the circularity value $[76,86]$. The effect of feed rate can be seen more clearly in holes drilled under dry conditions due to higher distortions in the hole and drill which steadily deteriorates with an increment in depth below the hole entry surface [87]. The variation between hole circularity at top and bottom was greater in holes under dry conditions. Using coolant is known to decreases the frictional load between the margin side of the drill and the machined hole wall; this in return would help the matrix in the composite to maintain its original support and protection to the overall structural integrity of the holes during the drilling process. In return, the induced mechanical damage on the hole walls is reduced, and the cutting of the fibres occurs regularly which gives better dimensional accuracy [70]. While the maximum circularity was $0.0287 \mathrm{~mm}$ for dry and $0.0167 \mathrm{~mm}$ for cryogenic conditions were noted. These maximum values were the result of the lowest $n=3000 \mathrm{rpm}$ with $f_{r}=500 \mathrm{~mm} / \mathrm{min}$ for dry drilling and $f_{r}=700 \mathrm{~mm} / \mathrm{min}$ for cryogenic conditions. The maximum values due to high $f_{r}$ might be either due to the rise in cutting forces or the faster penetration of cutting tool that increased the hole deflection and vibrations in the cutting tool, hence the higher circularity $[66,88]$. However, at the bottom of the hole, the minimum and maximum circularity for the dry conditions was $0.0100 \mathrm{~mm}$ and $0.0247 \mathrm{~mm}$, respectively. Both minimum and maximum values were obtained at $n=3000 \mathrm{rpm}$ with $f_{r}=300 \mathrm{~mm} / \mathrm{min}$ and 500 $\mathrm{mm} / \mathrm{min}$, respectively. In the case of the cryogenic condition, the minimum circularity of 0.0037 was noted at $n=$ $7000 \mathrm{rpm}$ and $f_{r}=300 \mathrm{~mm} / \mathrm{min}$. Also, the maximum circularity of $0.0177 \mathrm{~mm}$ was observed at $n$ of $3000 \mathrm{rpm}$ and $f_{r}=$ $700 \mathrm{~mm} / \mathrm{min}$. It is also found that under dry drilling, the depth of deformation increases as the rate of feed increases.

Table 3 and Fig. 5 shows that the spindle speed was the most dominant factor on circularity at the top, while the cryogenic coolant had the highest impact on circularity at the bottom with $40.85 \%$; this indicates that the cryogenic cooling could provide more stable circularity throughout the hole depth due to improved heat removal from the cutting zone. Similar results were reported by Shah et al. [89] which found that using cryogenic coolants reduced hole circularity when drilling metals over dry and flood cooling. The feed rate and spindle speed had a somewhat similar contribution on hole circularity at the bottom with $18 \%$ and $7.26 \%$, respectively. However, the effects of the feed rate and the spindle speed on hole circularity are quite complicated. For example, the trends in circularity at the top and the bottom vary significantly when drilling metals. It is speculated that there non-linear variations in hole circularity are present in the hole due to other untested input parameters such as workpiece fixture or vibrations and deflections occurring in the drill and damping characteristics $[90,91]$. This was evident from the ANOVA analysis which showed the presence of a large error.
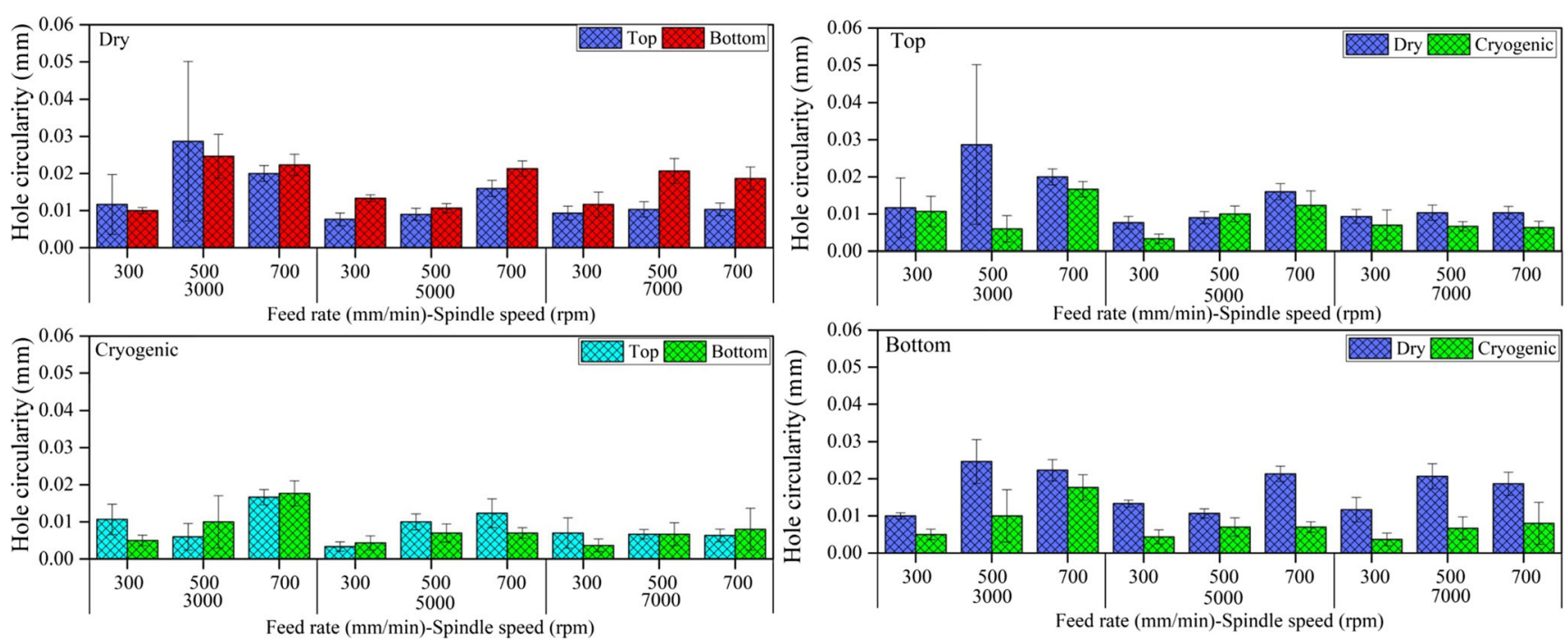

Fig. 4 Average hole circularity in dry and cryogenic conditions 

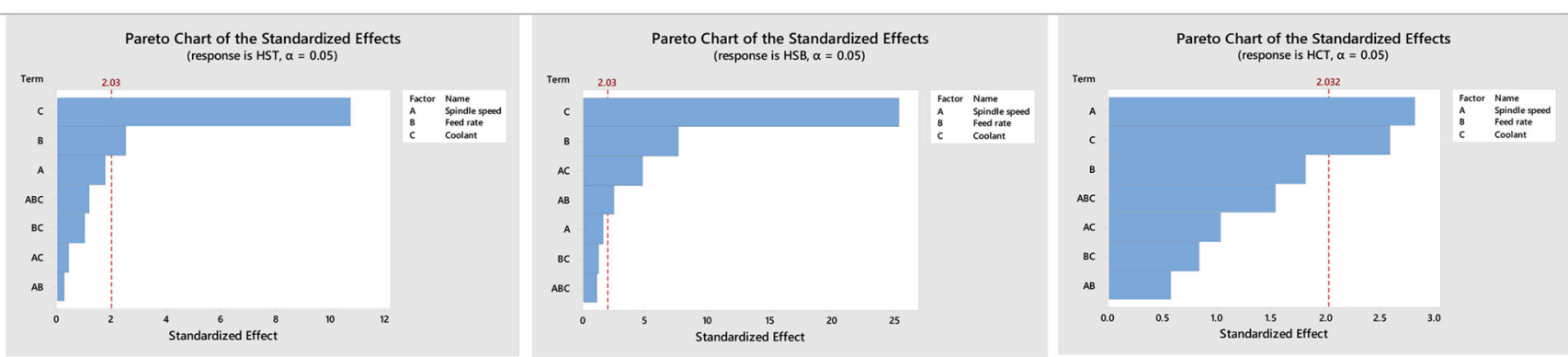

(a)

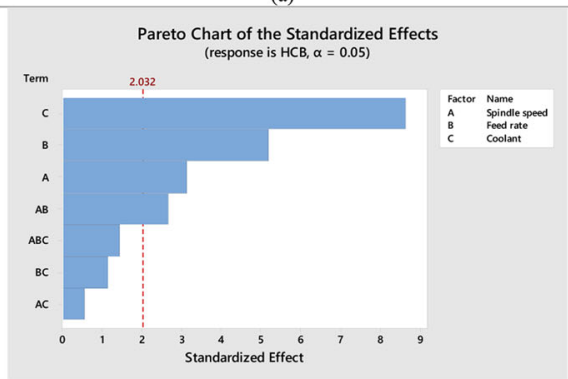

(b)
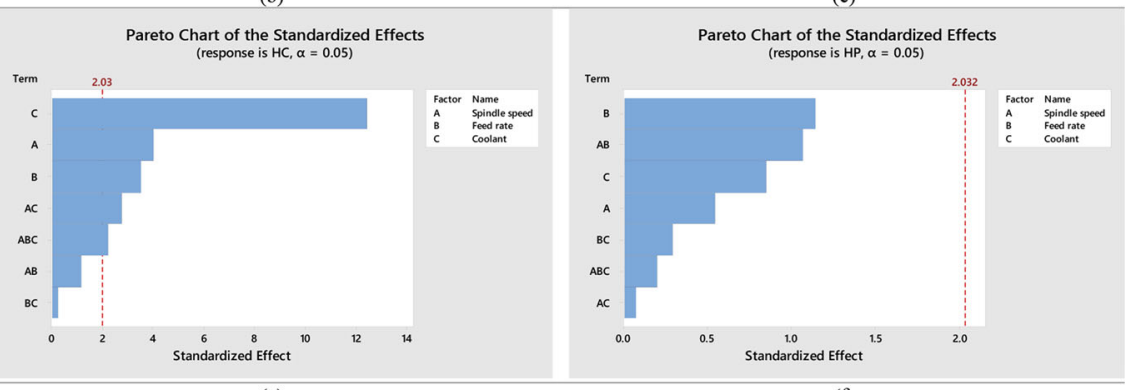

(f)

Fig. 5 Pareto charts for a hole size at top $\mathbf{b}$ hole size at bottom $\mathbf{c}$ circularity at top $\mathbf{d}$ circularity at bottom $\mathbf{e}$ cylindricity $\mathbf{f}$ perpendicularity

\subsection{Hole cylindricity and perpendicularity analysis}

Measuring the hole perpendicularity is a critical issue for aeronautical structures since the structural loading could be transferred through fuselage skin panels by riveted fastener holes at lap joints [92, 93]. Holes with poor perpendicularity tended to minimise the area of contact between the rivet and the hole walls which leads to stress concentrations that ultimately reduce the fatigue life of riveted structures [5]. Figure 6 shows the comparison of cylindricity and perpendicularity of S2/ FM94 glass fibre composites between dry and cryogenic conditions depending on cutting parameters. Considering all data, cylindricity increases with an increase in feed rate, but the same trend is not observed for spindle speed. It is well known that thrust forces increases linearly depending on an increase in the feed rate [55]. Vibration amplitude is a function of force and has a significant influence on circularity [94]. It was also noted that thrust force and torque cause compression, bending, and shear stresses and these loads give rise to cylindricity and deviation from nominal hole size [95]. When comparing the machining conditions, cryogenic machining significantly improves cylindricity. Minimum hole
Fig. 6 Average hole perpendicularity and cylindricity of holes in dry and cryogenic conditions
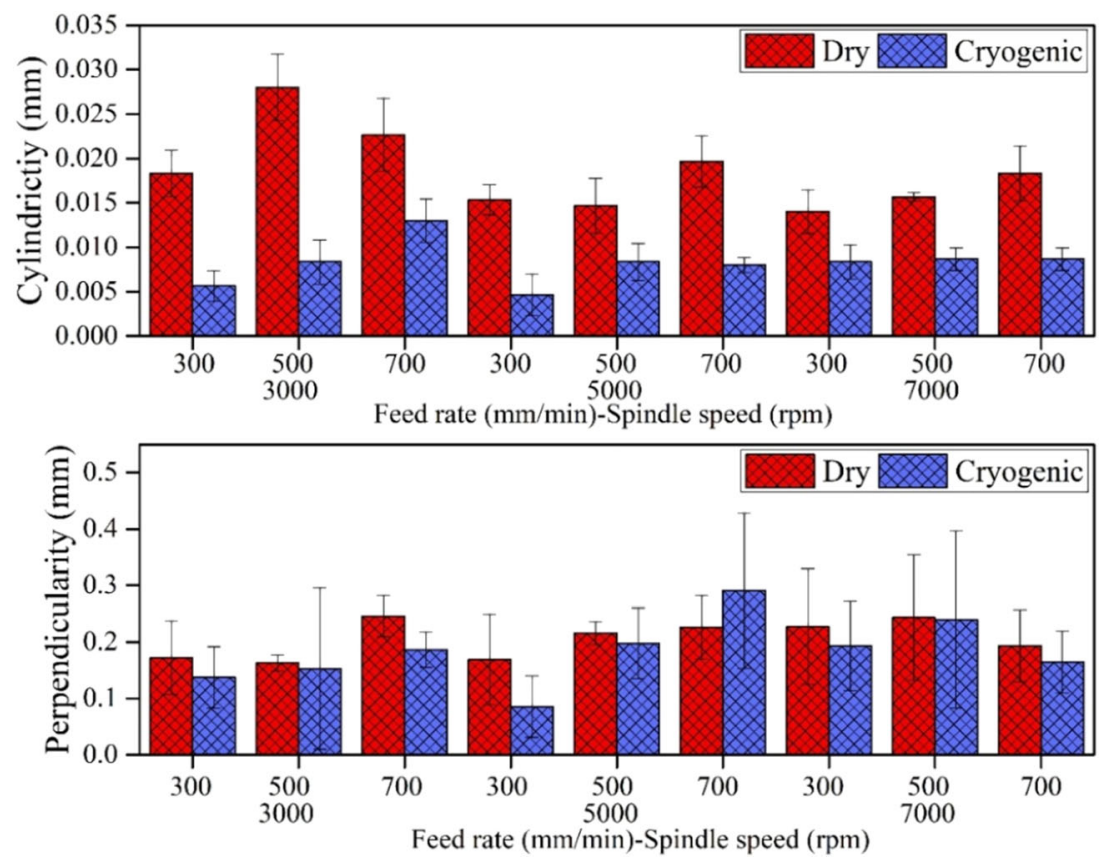
cylindrically of $0.0047 \mathrm{~mm}$ was obtained at moderate $n$ of $5000 \mathrm{rpm}$ with $f_{r}$ of $300 \mathrm{~mm} / \mathrm{min}$ under cryogenic condition, while the maximum was $0.028 \mathrm{~mm}$ occurred at low $n$ of $3000 \mathrm{rpm}$ with $f_{r}$ of $500 \mathrm{~mm} / \mathrm{min}$ under dry condition. In the all cutting combination tested range, cryogenic machining provides less deviation for cylindricity. Ghasemi et al. [94] reported that higher temperatures occurred during drilling cause higher thermal stresses and cylindricity is directly affected by the thermal loads. In cryogenic conditions, liquid nitrogen would carry away heat during the drilling process, and less thermal damage occurs on the hole surface [96].

In drilling, perpendicularity is the deviation of the hole axis from the ideal cylinder axis with respect to the specified reference point. This geometrical defect reduces the load-bearing capacity of bolted joints causing stress concentration around hole edges $[97,98]$. The results show perpendicularity increases depending on an increase in feed rate and spindle speed, but the influence of the feed rate is more dominant. This was also reported in past studies which indicated that perpendicularity is reduced when drilling at higher spindle speeds and lower feed rates [97, 99-101]. The increase in perpendicularity depending on the cutting parameters can be explained by the same phenomenon in cylindricity, namely, tool vibration. On the other hand, it is seen that the cryogenic condition has hardly any effect on the perpendicularity. It is concluded from the results that cutting temperature is not effective on perpendicularity contrary to other geometrical defects. This agrees with the previous study which found that machining coolants did not have an impact on the hole perpendicularity; instead, it was the size and type of cutting tool used which influenced perpendicularity [102]. The minimum perpendicularity is $0.0853 \mathrm{~mm}$ obtained at moderate $n$ of $5000 \mathrm{rpm}$ with $f_{r}$ of $300 \mathrm{~mm} / \mathrm{min}$ under cryogenic condition. The ANOVA results and Pareto charts given in Table 3 and Fig. 5 show that the coolant was the most significant factor affecting the cylindricity of the hole with $60.71 \%$, while both cutting parameters had a minor impact and somewhat equal. For perpendicularity, it appears that the ANOVA is unable to determine the effect of the input parameters. However, conclusions can be made from analysing Fig. 6. In addition, it was observed that the average perpendicularity of holes under cryogenic cooling was slightly lower than their counterparts under dry condition. It is worth noting that the hole perpendicularity data was inconsistent (i.e. poor repeatability), this would imply that additional factors that were not evaluated in the current study could have had an influence on hole perpendicularity [5]. For example, the hole position in the workpiece and the clamping setup, such factors will be investigated in a future study.

Previous study by Wang et al. [80] reported that optimum hole quality for composites is highly dependent on the temperatures at the cutting zone. Their study showed that maintaining the drilling temperature between the upper limit for brittle deformation and the lowest limit of the glass transition zone temperature causes the interlaminar fracture toughness, anti-deformation capacity and interfacial shear strength of the composite to increase, thereby reducing the likelihood of drilling damage. The formation of higher temperatures during drilling process leads to undesirable thermal damage to the machined holes due to the thermal instability of resin matrix composites [80]. The interfacial shear strength is influenced by the increase in drilling temperatures such that when temperature in the cutting zone exceeds that of the resin glass transition temperature, the interfacial shear strength is reduced which have an unfavourable effect on the machining process [80]. Under cryogenic conditions, it can be safely assumed that the drilling temperature at the cutting zone is unlikely to reach the resin glass transition temperature. On the contrary, the low cryogenic temperature of liquid nitrogen might promote increased interfacial shear strength and, therefore, might lead to the reduction in certain hole geometrical tolerances apart from the hole size due to brittle deformation. It is also known that the fracture toughness has direct impact on the exit delamination when drilling composites [80, 103]. Indeed, increase the fracture toughness can improve the critical thrust force and reduce the probability of delamination [103]. It was previously reported that the fracture toughness of a composite increases exponentially with temperature. However, unrecovered deformation occurs in the glass transition temperature range which negatively influences drilling quality and leads to more defect on the borehole surfaces [80]. This in return might explain the somewhat higher circularity, perpendicularity and cylindricity found in holes drilled under dry drilling conditions compared to those drilled under cryogenic conditions.

Figure 7 shows SEM images of inner borehole wall condition. It was observed that the damages and distortions in the hole walls were influenced by the angle at which the cutting edge of the tool is cutting the fibres. The fibres were subjected to alternating torsion and compression prior shearing by the cutting edges. This in return would produce an elliptical hole where the minor axis of the ellipse is in the same direction of the fibres [51]. In addition, better surface finish was achieved when using cryogenic cooling which might have influenced the hole geometrical tolerances [55]. Evidence from SEM inspection indicates that under dry drilling condition, the defects in the borehole walls are mainly characterised by the normal mechanical properties and fracture mechanisms of the carbon fibres themselves [70], while the damaging effect of the drilling process onto the hole walls is somewhat reduced under cryogenic cooling. It is important to note that under dry drilling condition, debris in the form of broken glass fibre are strongly present onto the hole walls, which supports the fact that powdery glass fibre chips tend to stick onto the cutting tool surface and the hole walls due to temperature rise at the cutting zone. With regard to the overall hole surface quality, 
Fig. 7 SEM images of holes inner surfaces at $3000 \mathrm{rpm}$ and 500 $\mathrm{mm} / \mathrm{min}$ under $\mathbf{a}$ dry $\mathbf{b}$ cryogenic



holes drilled using cryogenic cooling were found to have smoother surfaces than holes drilled under dry conditions using same cutting parameters [55].

Figure 8 shows the morphologies of the hole walls drilled under dry and cryogenic conditions. It was observed that both drilling conditions exhibit similar damage features [55]. Enlargement of the severely damaged areas in the inspected holes indicates that the defects were mainly surface cavities and fibre pull-outs. Fibre bending was more common in holes drilled under dry conditions as shown in Fig. 8 a and c. The fibres which were cut by the cutting tool but remained intact with in the matrix appeared to be severely distorted, deformed and bent; the fibres were irregularly scattered and pointing out in different direction as shown in Fig. 8a. This observation reflects that there was fierce frictional behaviour between the drill, the chip and the cut hole surface during the drilling operation [70], while the fibres found in holes drilled under cryogenic conditions appeared to be less damage and more uniform. It was observed that matrix loss was more severe in holes drilled under dry conditions due to thermal degradation of the epoxy matrix at high cutting temperatures, while under cryogenic conditions, the most noticeable form of damage was characterised by fibre pull outs as it can be seen in Fig. $8 \mathrm{~b}$ and $\mathrm{d}$. The extremely low temperatures induced by the cryogenic cooling during the drilling process appear to limit damages in fibre/matrix due to thermal degradation and high temperatures. It was also observed that under dry conditions, the fibre/matrix tended to stretch and overlap which could be due to rise in drilling temperatures and difference in the thermal conductivities of the fibres/matrix in different directions. This in return would explain the smaller hole size found in holes drilled under dry conditions. Moreover, the uncut fibres protruding outwards lack any form of support from the resin. Those extended fibres can easily break and separate from the hole surface and suppressed into the interlayers during the subsequent drilling operation as it can be seen from Fig. $8 \mathrm{c}$ and d.

Figure 9 shows the conditions of the cutting tools after the drilling tests. As seen from the images, minimal tool wear was formed in all the tools used in the drilling tests. Also, it can be


Fig. 8 Morphologies of the hole walls drilled under a cryogenic bath at $3000 \mathrm{rpm}$ and $700 \mathrm{~mm} / \mathrm{min}$ b cryogenic bath at $5000 \mathrm{rpm}$ and $500 \mathrm{~mm} /$ min $\mathbf{c}$ dry condition at $5000 \mathrm{rpm}$ and $700 \mathrm{~mm} / \mathrm{min} \mathbf{d}$ dry condition at $7000 \mathrm{rpm}$ and $700 \mathrm{~mm} / \mathrm{min}$ 
seen that glass fibre dust powder scattered all over the drills. Figure $8 \mathrm{a}$ and $\mathrm{b}$ shows that very limited signs of tool wear on the chisel edge and the cutting edges formed for both dry and cryogenic tests. This is mainly due to the high hardness of the carbide drills and TiAlN coating providing better resistance against abrasion. Moreover, absence of any significant tool wear could be due to the limited number of holes drilled using each tool. In addition, due the abrasive nature of glass fibres, it appears that excessive wear will form faster at the outer corners of the drills as shown in Fig. 8 a and b. However, this claim must be confirmed by drilling additional holes, which will be carried out in a future study. No chipping was found on the cutting lips of the tools as shown in Fig. $8 \mathrm{c}$ and d which means that the cutting parameters used in the study do not promote high thermal instability that could deteriorate the coating on the tool. Therefore, it is a conclusion on whether cryogenic cooling can prolong tool life cannot be concluded from this study, and further testing is required to investigate its impact on tool wear compared to dry drilling.

\section{Conclusion}

The current study investigated the effect of drilling holes in S2/FM94 glass fibre composite in a cryogenic bath of liquid nitrogen. The study aims to evaluate the effect of cryogenic cooling and cutting parameters (spindle speed and feed rate) on the hole and dimensional tolerances. The results from cryogenic drilling tests are compared against results from dry drilling tests conducted under the same cutting parameters and using the same cutting tools. The following can be concluded:
- Oversized holes were produced in all holes at top and bottom locations under cryogenic conditions regardless of the cutting parameters used. ANOVA analysis showed that the coolant had the most significant contribution on hole size $(65-80 \%)$ followed by a minor contribution by the feed rate.

- The deviation of hole size from the nominal hole diameter was greater when using cryogenic bath at top and bottom; this indicates that cryogenic bath might not be suitable for drilling S2 glass fibre composites. The deviation was greater than $20 \mu \mathrm{m}$ which exceeds recommendation for hole size in aeronautical structures.

- Hole circularity found under cryogenic bath was always less than their counterparts under the dry condition at top and bottom locations. It was also found that in general, hole circularity at the bottom was greater than at top under dry conditions especially at higher cutting parameters, while for cryogenic tests, hole circularity at top and bottom were relatively similar which indicates that cryogenic bath is effective in minimising hole circularity, especially at high cutting parameters.

- Hole circularity at the top was influenced by the feed rate and cooling, while at the bottom, the coolant showed the highest influence with $40 \%$ followed by the spindle speed and feed rate, respectively.

- Hole cylindricity was significantly reduced under cryogenic conditions and was not highly affected by the increase in the feed rate similar to what was observed in dry drilling tests. ANOVA results showed that cryogenic cooling was the major factor affecting cylindricity with $60 \%$.
Fig. 9 Post machining tool condition under $\mathbf{a}$ and $\mathbf{c}$ dry $\mathbf{b}$ and d cryogenic conditions
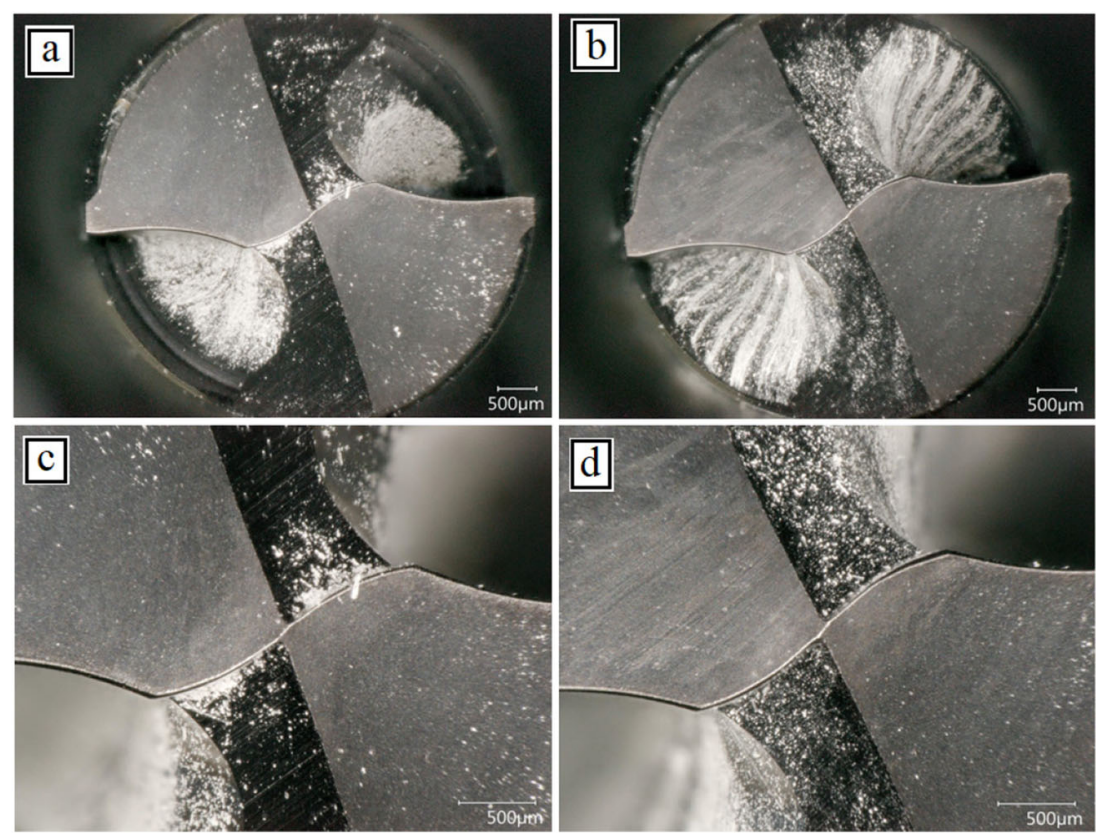
- Hole perpendicularity in dry and cryogenic tests was similar; the use of cryogenic cooling did not seem to have any impact. However, it was observed that in general, the average perpendicularity in cryogenic tests was slightly lower than their counterparts in dry tests.

- Considering that producing holes with eliminated/reduced circularity, cylindricity and perpendicularity, cryogenically assisted drilling of S2 glass fibre composite can be a preferred approach for aerospace applications.

Acknowledgements The authors would like to sincerely thank Mr. William Keeble for assistance with the measurements of hole metrics.

Author contribution All the authors have contributed equally to the production of the present paper.

Data availability All data that support the findings of this study are available from the corresponding author upon reasonable request.

\section{Declarations}

Conflict of interest The authors declare no competing interests.

Open Access This article is licensed under a Creative Commons Attribution 4.0 International License, which permits use, sharing, adaptation, distribution and reproduction in any medium or format, as long as you give appropriate credit to the original author(s) and the source, provide a link to the Creative Commons licence, and indicate if changes were made. The images or other third party material in this article are included in the article's Creative Commons licence, unless indicated otherwise in a credit line to the material. If material is not included in the article's Creative Commons licence and your intended use is not permitted by statutory regulation or exceeds the permitted use, you will need to obtain permission directly from the copyright holder. To view a copy of this licence, visit http://creativecommons.org/licenses/by/4.0/.

\section{References}

1. marketsandMarkets ${ }^{\mathrm{TM}}$ (2020) Impact of COVID-19 on global composites market, Global Forecast to 2025. [cited 2020 19/08]. Available from: https://www.marketsandmarkets.com/MarketReports/composite-market-200051282.html

2. Gudmundsson S (2013) General aviation aircraft design: applied methods and procedures. Butterworth-Heinemann

3. Kinsella M, Murray D, Crane D, Mancinelli J, Kranjc M (2001) Mechanical properties of polymeric composites reinforced with high strength glass fibers. in International SAMPE Technical Conference

4. Yuan P, Lai T, Li Y, Han W, Lin M, Zhu Q, Liu Y, Shi Z (2016) The attitude adjustment algorithm in drilling end-effector for aviation. Adv Mech Eng 8(1). https://doi.org/10.1177/ 1687814016629348

5. Giasin K (2018) The effect of drilling parameters, cooling technology, and fiber orientation on hole perpendicularity error in fiber metal laminates. Int J Adv Manuf Technol 97(9-12):4081-4099. https://doi.org/10.1007/s00170-018-2241-1
6. Hocheng H (2011) Machining technology for composite materials: principles and practice. Elsevier

7. Pimenov DY, Mia M, Gupta MK, Machado AR, Tomaz ÍV, Sarikaya M, Wojciechowski S, Mikolajczyk T, Kapłonek W (2021) Improvement of machinability of Ti and its alloys using cooling-lubrication techniques: a review and future prospect. J Mater Res Technol 11:719-753. https://doi.org/10.1016/j.jmrt. 2021.01.031

8. Sarikaya M, Gupta MK, ItaloTomaz M, Danish M, Mia S, Rubaieef M, Jamil DYP, Khanna N (2020) Cooling techniques to improve the machinability and sustainability of light-weight alloys: a state-of-the-art review. J Manuf Process 62:179-201. https://doi.org/10.1016/j.jmapro.2020.12.013

9. Balan ASS, Chidambaram K, Kumar AV, Krishnaswamy H, Pimenov DY, Giasin K, Nadolny K (2021) Effect of cryogenic grinding on fatigue life of additively manufactured maraging steel. Materials 14(5):1245. https://doi.org/10.3390/ma14051245

10. Yildiz Y, Nalbant M (2008) A review of cryogenic cooling in machining processes. Int J Mach Tools Manuf 48(9):947-964. https://doi.org/10.1016/j.ijmachtools.2008.01.008

11. Pušavec F, Stoić A, Kopač J (2009) The role of cryogenics in machining processes. Tehnički vjesnik 16(4):3-10

12. Giasin K, Barouni A, Dhakal HN, Featherson C, Redouane Z, Morkavuk S, Koklu U (2020) Microstructural investigation and hole quality evaluation in S2/FM94 glass-fibre composites under dry and cryogenic conditions. J Reinf Plast. https://doi.org/10. $1177 / 0731684420958479$

13. Beumler T (2004) Flying GLARE: A contribution to aircraft certification issues in strength properties in non-damaged and fatigue damaged GLARE structures. Delft University Press

14. Rezende BA, Silveira ML, Vieira LM, Abrão AM, Faria PEd, Rubio JCC (2016) Investigation on the effect of drill geometry and pilot holes on thrust force and burr height when drilling an aluminium/PE sandwich material. Materials 9(9):774. https://doi. org/10.3390/ma9090774

15. Senthilkumar BMA (2016) Mechanical and machinability characteristics of fiber metal laminates. LAP Lambert Academic Publishing 60

16. Khashaba U, El-Sonbaty I, Selmy A, Megahed A (2012) Drilling analysis of woven glass fiber-reinforced/epoxy composites. J Compos Mater 47:191-205. https://doi.org/10.1177/ 0021998312438620

17. Krishnaraj V (2008) Effects of drill points on glass fibre reinforced plastic composite while drilling at high spindle speed. In: Proceedings of the World Congress on Engineering. London-U.K

18. Kim GW, Lee KY (2005) Critical thrust force at propagation of delamination zone due to drilling of FRP/metallic strips. Compos Struct 69(2):137-141. https://doi.org/10.1016/j.compstruct.2004. 06.013

19. Palanikumar K, Rubio JC, Abrao A, Correia AE, Davim JP (2008) Influence of drill point angle in high speed drilling of glass fiber reinforced plastics. J Compos Mater 42(24):2585-2597. https:// doi.org/10.1177/0021998308096322

20. Arul S, Vijayaraghavan L, Malhotra S, Krishnamurthy R (2006) Influence of tool material on dynamics of drilling of GFRP composites. Int J Adv Manuf Technol 29(7-8):655-662. https://doi. org/10.1007/s00170-005-2581-5

21. Kim D, Ramulu M (2007) Study on the drilling of titanium/ graphite hybrid composites. J Eng Mater Technol 129(3):390 396. https://doi.org/10.1115/1.2744397

22. Sánchez Carrilero M, Álvarez M, Ares E, Astorga J, Cano M, Marcos M (2006) Dry drilling of fiber metal laminates CF/ AA2024. A preliminary study. in Materials science forum. Trans Tech Publ. https://doi.org/10.4028/www.scientific.net/MSF.526. 73 
23. Mehbudi P, Baghlani V, Akbari J, Bushroa A, Mardi N (2013) Applying ultrasonic vibration to decrease drilling-induced delamination in GFRP laminates. Procedia Cirp 6:577-582. https://doi. org/10.1016/j.procir.2013.03.097

24. Khashaba U, El-Sonbaty I, Selmy A, Megahed A (2010) Machinability analysis in drilling woven GFR/epoxy composites: part I-Effect of machining parameters. Compos A: Appl Sci Manuf 41(3):391-400. https://doi.org/10.1016/j.compositesa. 2009.11.006

25. Coesel JFW (1994) Drilling of fibre-metal laminates, in faculty of aerospace engineering. Delft University of Technology, p 63

26. Tyczynski P, Lemanczyk J, Ostrowski R (2014) Drilling of CFRP, GFRP, glare type composites. Aircr Eng Aerosp Technol 86(4): 312-322. https://doi.org/10.1108/AEAT-10-2012-0196

27. Zitoune R, Collombet F, Lopez GH (2008) Experimental and analytical study of the influence of HexFit ${ }^{\circledR}$ glass fibre composite manufacturing process on delamination during drilling. Int J Mach Mach Mater 3(3-4):326-342. https://doi.org/10.1504/IJMMM. 2008.020967

28. Lin S-C, Shen J-M (1999) Drilling unidirectional glass fiberreinforced composite materials at high speed. J Compos Mater 33(9):827-851. https://doi.org/10.1177/002199839903300903

29. Pawar OA, Gaikhe YS, Tewari A, Sundaram R, Joshi SS (2015) Analysis of hole quality in drilling GLARE fiber metal laminates. Compos Struct 123:350-365. https://doi.org/10.1016/j. compstruct.2014.12.056

30. Vankanti VK, Ganta V (2014) Optimization of process parameters in drilling of GFRP composite using Taguchi method. J Mater Res Technol 3(1):35-41. https://doi.org/10.1016/j.jmrt.2013.10.007

31. Velayudham A, Krishnamurthy R, Soundarapandian T (2005) Evaluation of drilling characteristics of high volume fraction fibre glass reinforced polymeric composite. Int J Mach Tools Manuf 45(4-5):399-406. https://doi.org/10.1016/j.jmrt.2013.10.007

32. Rubio JCC, da Silva LJ, de Oliveira Leite W, Panzera TH, Ribeiro Filho SLM, Davim JP (2013) Investigations on the drilling process of unreinforced and reinforced polyamides using Taguchi method. Compos Part B 55:338-344. https://doi.org/10.1016/j. compositesb.2013.06.042

33. Singh I, Bhatnagar N, Viswanath P (2008) Drilling of unidirectional glass fiber reinforced plastics: experimental and finite element study. Mater Des 29(2):546-553. https://doi.org/10.1016/ j.matdes.2007.01.029

34. Işık B, Ekici E (2010) Experimental investigations of damage analysis in drilling of woven glass fiber-reinforced plastic composites. Int J Adv Manuf Technol 49(9-12):861-869. https://doi. org/10.1007/s00170-009-2440-x

35. Davim JP, Reis P, Antonio CC (2004) Experimental study of drilling glass fiber reinforced plastics (GFRP) manufactured by hand lay-up. Compos Sci Technol 64(2):289-297. https://doi. org/10.1016/S0266-3538(03)00253-7

36. Latha B, Senthilkumar V, Palanikumar K (2011) Influence of drill geometry on thrust force in drilling GFRP composites. J Reinf Plast Compos 30(6):463-472. https://doi.org/10.1177/ 0731684410397681

37. Kilickap E (2010) Investigation into the effect of drilling parameters on delamination in drilling GFRP. J Reinf Plast Compos 29(23):3498-3503. https://doi.org/10.1177/0731684410386271

38. Mudhukrishnan M, Hariharan P, Palanikumar K (2020) Measurement and analysis of thrust force and delamination in drilling glass fiber reinforced polypropylene composites using different drills. Measurement 149:106973. https://doi.org/10. 1016/j.measurement.2019.106973

39. Ramesh B, Elayaperumal A (2012) Optimization of process parameter levels during drilling high fiber volume fraction nonlaminated GFRP polymeric composites. Int J Sci Eng Appl 1(2):120-126. https://doi.org/10.7753/IJSEA0102.1007
40. Mohan N, Kulkarni S, Ramachandra A (2007) Delamination analysis in drilling process of glass fiber reinforced plastic (GFRP) composite materials. J Mater Process Technol 186(1-3): 265-271. https://doi.org/10.1016/j.jmatprotec.2006.12.043

41. Ranganathan S, Senthilvelan T, Gopalakannan S (2012) Multiple performance optimization in drilling of GFRP composites using grey analysis. In: IEEE-International Conference On Advances In Engineering, Science And Management (ICAESM-2012). IEEE.

42. Sarma P, Karunamoorthy L, Palanikumar K (2009) Surface roughness parameters evaluation in machining GFRP composites by PCD tool using digital image processing. J Reinf Plast Compos 28(13):1567-1585. https://doi.org/10.1177/0731684408089858

43. Sureshkumar M, Lakshmanan D, Murugarajan A (2014) Experimental investigation and mathematical modelling of drilling on GFRP composites. Mater Res Innov 18:S1-S97. https:// doi.org/10.1179/1432891713Z.000000000361

44. Kilickap E (2010) Optimization of cutting parameters on delamination based on Taguchi method during drilling of GFRP composite. Expert Syst Appl 37(8):6116-6122. https://doi.org/10. 1016/j.eswa.2010.02.023

45. Mathew J, Ramakrishnan N, Naik NK (1999) Investigations into the effect of geometry of a trepanning tool on thrust and torque during drilling of GFRP composites. J Mater Process Technol 91(1):1-11. https://doi.org/10.1016/S0924-0136(98)00416-6

46. Singh I, Bhatnagar N (2006) Drilling of uni-directional glass fiber reinforced plastic (UD-GFRP) composite laminates. Int J Adv Manuf Technol 27(9-10):870-876. https://doi.org/10.1007/ s00170-004-2280-7

47. Abrão AM, Rubio JCC, Faria PE, Davim JP (2008) The effect of cutting tool geometry on thrust force and delamination when drilling glass fibre reinforced plastic composite. Mater Des 29(2): 508-513. https://doi.org/10.1016/j.matdes.2007.01.016

48. Gaitonde VN, Karnik SR, Rubio JC, Correia AE, Abrão AM, Davim JP (2008) Analysis of parametric influence on delamination in high-speed drilling of carbon fiber reinforced plastic composites. J Mater Process Technol 203(1):431-438. https://doi.org/ 10.1016/j.jmatprotec.2007.10.050

49. Campos Rubio J, Abrao AM, Faria PE, Correia AE, Davim JP (2008) Effects of high speed in the drilling of glass fibre reinforced plastic: evaluation of the delamination factor. Int $\mathrm{J}$ Mach Tools Manuf 48(6):715-720. https://doi.org/10.1016/j.ijmachtools. 2007.10.015

50. Bosco MAJ, Palanikumar K, Prasad BD, Velayudham A (2013) Influence of machining parameters on delamination in drilling of GFRP-armour steel sandwich composites. Procedia Engineering 51:758-763. https://doi.org/10.1016/j.proeng.2013.01.108

51. Faria P, Campos Rubio J, Abrao A, Davim J (2009) Dimensional and geometric deviations induced by drilling of polymeric composite. J Reinf Plast Compos 28(19):2353-2363. https://doi.org/ $10.1177 / 0731684408092067$

52. Kim D, Ramulu M (2004) Drilling process optimization for graphite/bismaleimide-titanium alloy stacks. Compos Struct 63(1): 101-114. https://doi.org/10.1016/S0263-8223(03)00137-5

53. Arun K, Ramesh Kannan C, Stalin B (2020) The effect of cryogenically treated drilling tool on GFRP composite drilling holes-a comparative study. Materials Today: Proceedings 33:4362-4367. https://doi.org/10.1016/j.matpr.2020.07.579

54. Abish J, Samal P, Narenther M, Kannan C, Balan A (2018) Assessment of drilling-induced damage in CFRP under chilled air environment. Mater Manuf Process 33(12):1361-1368. https://oi.org/10.1080/10426914.2017.1415452

55. Giasin K, Barouni A, Dhakal HN, Featherson C, Redouane Z, Morkavuk S, Koklu U (2020) Microstructural investigation and hole quality evaluation in S2/FM94 glass-fibre composites under dry and cryogenic conditions. J Reinf Plast Compos 40:273-293. https://doi.org/10.1177/0731684420958479 
56. Sun D, Lemoine P, Keys D, Doyle P, Malinov S, Zhao Q, Qin X, Jin Y (2018) Hole-making processes and their impacts on the microstructure and fatigue response of aircraft alloys. Int J Adv Manuf Technol 94(5-8):1719-1726. https://doi.org/10.1007/ s00170-016-9850-3

57. Krishnaraj V, Prabukarthi A, Ramanathan A, Elanghovan N, Senthil Kumar M, Zitoune R, Davim JP (2012) Optimization of machining parameters at high speed drilling of carbon fiber reinforced plastic (CFRP) laminates. Compos Part B 43(4):17911799. https://doi.org/10.1016/j.compositesb.2012.01.007

58. Ameur M, Habak M, Kenane M, Aouici H, Cheikh M (2017) Machinability analysis of dry drilling of carbon/epoxy composites: cases of exit delamination and cylindricity error. Int $\mathrm{J} \mathrm{Adv}$ Manuf Technol 88(9-12):2557-2571. https://doi.org/10.1007/ s00170-016-8967-8

59. Zitoune R, Krishnaraj V, Collombet F (2010) Study of drilling of composite material and aluminium stack. Compos Struct 92(5): 1246-1255. https://doi.org/10.1016/j.compstruct.2009.10.010

60. Alizadeh Ashrafi S, Miller PW, Wandro KM, Kim D (2016) Characterization and effects of fiber pull-outs in hole quality of carbon fiber reinforced plastics composite. Materials 9(10):828. https://doi.org/10.3390/ma9100828

61. Gowda BU, Ravindra H, Prakash GN, Nishanth P, Ugrasen G (2015) Optimization of process parameters in drilling of epoxy Si3N4 composite material. Materials Today: Proceedings 2(4-5): 2852-2861. https://doi.org/10.1016/j.matpr.2015.07.300

62. Angelone R, Caggiano A, Improta I, Nele L, Teti R (2019) Characterization of hole quality and temperature in drilling of Al/CFRP stacks under different process condition. Procedia CIRP 79:319-324. https://doi.org/10.1016/j.procir.2019.02.074

63. Xia T, Kaynak Y, Arvin C, Jawahir I (2016) Cryogenic coolinginduced process performance and surface integrity in drilling CFRP composite material. Int J Adv Manuf Technol 82(1-4): 605-616. https://doi.org/10.1007/s00170-015-7284-y

64. Vlot A, Gunnink JW (2001) Fibre metal laminates: an introduction. Springer

65. Botelho EC, Silva RA, Pardini LC, Rezende MC (2006) A review on the development and properties of continuous fiber/epoxy/aluminum hybrid composites for aircraft structures. Mater Res 9(3): 247-256. https://doi.org/10.1590/S1516-14392006000300002

66. Kurt M, Kaynak Y, Bagci E (2008) Evaluation of drilled hole quality in Al 2024 alloy. Int J Adv Manuf Technol 37(11-12): 1051-1060. https://doi.org/10.1007/s00170-007-1049-1

67. Bono M, Ni J (2001) The effects of thermal distortions on the diameter and cylindricity of dry drilled holes. Int J Mach Tools Manuf 41(15):2261-2270. https://doi.org/10.1016/S08906955(01)00047-5

68. Giasin K, Hawxwell J, Sinke J, Dhakal H, Köklü U, Brousseau E (2020) The effect of cutting tool coating on the form and dimensional errors of machined holes in GLARE® fibre metal laminates. Int J Adv Manuf Technol 107:1-16. https://doi.org/10. 1007/s00170-020-05211-2

69. Aamir M, Tolouei-Rad M, Giasin K, Nosrati A (2019) Recent advances in drilling of carbon fiber-reinforced polymers for aerospace applications: a review. Int J Adv Manuf Technol 105(5-6): 2289-2308. https://doi.org/10.1007/s00170-019-04348-z

70. Xu J, Ji M, Chen M, El Mansori M (2020) Experimental investigation on drilling machinability and hole quality of CFRP/ Ti6Al4V stacks under different cooling conditions. Int J Adv Manuf Technol 109(5):1527-1539. https://doi.org/10.1007/ s00170-020-05742-8

71. Shyha I, Soo SL, Aspinwall D, Bradley S, Perry R, Harden P, Dawson S (2011) Hole quality assessment following drilling of metallic-composite stacks. Int J Mach Tools Manuf 51(7-8):569578. https://doi.org/10.1016/j.ijmachtools.2011.04.007
72. Liu K (2012) Tungsten carbide: processing and applications. BoD-Books on Demand

73. Giasin K, Ayvar-Soberanis S, Hodzic A (2016) Evaluation of cryogenic cooling and minimum quantity lubrication effects on machining GLARE laminates using design of experiments. J Clean Prod 135:533-548. https://doi.org/10.1016/j.jclepro.2016. 06.098

74. Shokrani A, Leafe H, Newman ST (2019) Cryogenic drilling of carbon fibre reinforced plastic with tool consideration. Procedia CIRP 85:55-60. https://doi.org/10.1016/j.procir.2019.10.008

75. Giasin K, Dad A, Brousseau E, Pimenov D, Mia M, Morkavuk S, Koklu U (2021) The effects of through tool cryogenic machining on the hole quality in GLARE® fibre metal laminates. J Manuf Process 64:996-1012. https://doi.org/10.1016/j.jmapro.2021.02. 010

76. Nagaraj A, Uysal A, Jawahir I (2020) An Investigation of process performance when drilling carbon fiber reinforced polymer (CFRP) composite under dry, cryogenic and MQL environments. Procedia Manufacturing 43:551-558. https://doi.org/10.1016/j. promfg.2020.02.165

77. Rodríguez A, Calleja A, de Lacalle LNL, Pereira O, RubioMateos A, Rodríguez G (2021) Drilling of CFRP-Ti6Al4V stacks using CO2-cryogenic cooling. J Manuf Process 64:58-66. https:// doi.org/10.1016/j.jmapro.2021.01.018

78. Kumar D, Gururaja S, Jawahir I (2020) Machinability and surface integrity of adhesively bonded Ti/CFRP/Ti hybrid composite laminates under dry and cryogenic conditions. J Manuf Process 58: 1075-1087. https://doi.org/10.1016/j.jmapro.2020.08.064

79. Iqbal A, Zhao G, Zaini J, Gupta MK, Jamil M, He N, Nauman MM, Mikolajczyk T, Pimenov DY (2021) Between-the-holes cryogenic cooling of the tool in hole-making of Ti-6Al-4V and CFRP. Materials 14:795. https://doi.org/10.3390/ma14040795

80. Wang H, Zhang X, Duan Y (2018) Effects of drilling area temperature on drilling of carbon fiber reinforced polymer composites due to temperature-dependent properties. Int J Adv Manuf Technol 96(5):2943-2951. https://doi.org/10.1007/s00170-0181810-7

81. Giasin K (2017) Machining fibre metal laminates and A12024-T3 aluminium alloy, University of Sheffield

82. Gardiner G (2014) Hole quality defined, compositesworld

83. Brinksmeier E, Janssen R (2002) Drilling of multi-layer composite materials consisting of carbon fiber reinforced plastics (CFRP), titanium and aluminum alloys. CIRP Ann 51(1):87-90. https:// doi.org/10.1016/S0007-8506(07)61472-3

84. Everson CE, Hoessein Cheraghi S (1999) The application of acoustic emission for precision drilling process monitoring. Int $\mathrm{J}$ Mach Tools Manuf 39(3):371-387. https://doi.org/10.1016/ S0890-6955(98)00054-6

85. SANDVIK (2011) Improved hand-held hole making in composites. http://www.sandvik.coromant.com

86. Chandrasekharan V (1997) A model to predict the threedimensional cutting force system for drilling with arbitrary point geometry.

87. Chakravarthy VVK, Rajmohan T, Vijayan D, Palanikumar K (2021) Sustainable drilling of nano $\mathrm{SiC}$ reinforced $\mathrm{Al}$ matrix composites using MQL and cryogenic cooling for achieving the better surface integrity. Silicon. https://doi.org/10.1007/s12633-02100977-w

88. Giasin K, Ayvar-Soberanis S (2017) An Investigation of burrs, chip formation, hole size, circularity and delamination during drilling operation of GLARE using ANOVA. Compos Struct 159: 745-760. https://doi.org/10.1016/j.compstruct.2016.10.015

89. Shah P, Khanna N, Chetan (2020) Comprehensive machining analysis to establish cryogenic LN2 and LCO2 as sustainable cooling and lubrication techniques. Tribol Int 148:106314. https://doi.org/10.1016/j.triboint.2020.106314 
90. Abdelhafeez AM, Soo SL, Aspinwall DK, Dowson A, Arnold D (2015) Burr formation and hole quality when drilling titanium and aluminium alloys. Procedia CIRP 37:230-235

91. Giasin K, Hodzic A, Phadnis V, Ayvar-Soberanis S (2016) Assessment of cutting forces and hole quality in drilling A12024 aluminium alloy: experimental and finite element study. Int J Adv Manuf Technol 87(5-8):2041-2061. https://doi.org/10.1007/ s00170-016-8563-y

92. Bickford J (1998) Handbook of bolts and bolted joints. CRC press.

93. Gao Y, Wu D, Dong Y, Ma X, Chen K (2017) The method of aiming towards the normal direction for robotic drilling. Int $\mathrm{J}$ Precis Eng Manuf 18(6):787-794. https://doi.org/10.1007/ s12541-017-0094-4

94. Ghasemi AH, Khorasani AM, Gibson I (2018) Investigation on the effect of a pre-center drill hole and tool material on thrust force, surface roughness, and cylindricity in the drilling of Al7075. Materials 11(1):140. https://doi.org/10.3390/ma11010140

95. Álvarez-Alcón M, de Lacalle LNL, Fernández-Zacarías F (2020) Multiple sensor monitoring of CFRP drilling to define cutting parameters sensitivity on surface roughness, cylindricity and diameter. Materials 13(12):2796. https://doi.org/10.3390/ ma13122796

96. Xia T (2014) Investigation of drilling performance in cryogenic drilling on CFRP composite laminates, in Mechanical Engineering in the College of Engineering, University of Kentucky

97. Sheth S, George P (2016) Experimental investigation, prediction and optimization of cylindricity and perpendicularity during drilling of WCB material using grey relational analysis. Precis Eng 45:33-43. https://doi.org/10.1016/j.precisioneng.2016.01. 002

98. Liu X, Yang Y, Wang Y, Bao Y, Gao H (2017) Effects of hole perpendicularity error on mechanical performance of single-lap double-bolt composite joints. International J Polym Sci 2017:111. https://doi.org/10.1155/2017/2790198

99. Akanksha P (2014) Investigation of cutting parameters during drilling of mildsteel in context of cylindricity and perpendicularity, in Engineering. BVM Engineering College

100. Sheth S, Chauhan P, Modi BS, Pancholi A (2014) Study and investigate effect of cutting parameters in drilling on cylindricity and perpendicularity. in Proceedings of the fourth national conference on recent advances in manufacturing (RAM-2014), SVNIT, Surat

101. Yavuz M, Gökçe H (2017) Matkap geometrisinin delik kalitesi ve kesme performansina etkisi. http://dergipark.gov.tr/doi/10.16984/ saufenbilder.292019

102. Haan D, Batzer S, Olson W, Sutherland J (1997) An experimental study of cutting fluid effects in drilling. J Mater Process Technol 71(2):305-313. https://doi.org/10.1016/S0924-0136(97)00089-7

103. Gururaja S, Ramulu M (2009) Modified exit-ply delamination model for drilling FRPs. J Compos Mater 43(5):483-500. https://doi.org/10.1177/0021998308097677

Publisher's note Springer Nature remains neutral with regard to jurisdictional claims in published maps and institutional affiliations. 